\title{
The risk of muscle dysmorphia and the perception of change in retrospective, current and ideal self-image - preliminary study
}

\begin{abstract}
BACKGROUND
A specific type of causes of extended training and gym exercises is muscle dysmorphia. People with this disorder think that their current appearance is not satisfactory, and the focus on the perceived defect is great. The perceived defect usually is connected with body and muscle mass and body shape. According to the conceptual model of dysmorphia proposed by Grieve (2007), the aim of the study was to verify the thesis that the risk of muscle dysmorphia is associated with the negative self-image generalized based on physical appearance.
\end{abstract}

\section{PARTICIPANTS AND PROCEDURE}

Twelve women and 18 men, fulfilling the criteria of exercise addiction according to Pope, filled out the ACL scale, answering the questions concerning what kind of person they were before training, who they are now and what kind of person they would like to be. Also, they answered freely the questions concerning their feelings about training.

RESULTS

A significant difference between perceived retrospective and current self-image was observed. The people examined became, in their opinion, more self-confident, more dominating and independent, and they described themselves in more positive categories. However, there still is relatively a lot of aggression and anxiety. The analysis of the ideal self-image indicates that the presented image performs at least partly - the defence mechanism role. This is also confirmed by the analysis of the statements of the subjects examined, especially the question about the benefits resulting from the training.

\section{CONCLUSIONS}

The results confirm the role of the negative self-image in the risk of muscle dysmorphia. The exercises change self-assessment, but they do not solve the problems that were the reason for it. The characteristics of these problems in further research will facilitate therapy planning.

KEY WORDS

self-esteem; personality changes; muscle dysmorphia

Organizations - 1: Institute of Psychology, The John Paul II Catholic University of Lublin, Lublin, Poland .

2: Faculty of Christian Philosophy, Cardinal Stefan Wyszyński University, Warsaw, Poland

AUthors' CONTRIBUtion - A: Study design - B: Data collection · C: Statistical analysis · D: Data interpretation .

E: Manuscript preparation · F: Literature search G: Funds collection

CORResPonding Author - Dorota Mącik, Ph.D., Institute of Psychology, The John Paul II Catholic University of Lublin,

14 Racławickie Avenue, 20-950 Lublin, Poland, e-mail: dorota_macik@tlen.pl

TO CITE THIS ARTICLE - Mącik, D., \& Kowalska-Dąbrowska, M. (2015). The risk of muscle dysmorphia and the perception

of change in retrospective, current and ideal self-image - preliminary study. Health Psychology Report, 3(1), 24-34.

DOI: $10.5114 /$ hpr.2015.47087

RECEIVED 30.05.2014 · REVIEWED 20.06.2014 · ACCEPTED 22.09.2014 • PUBLISHED 25.11.2014 


\section{BACKGROUND}

Recent years in Poland have brought significant growth of interest in sport. Activities connected to running, cycling, skiing and all other available types of sport are widely popularised. Also encouraging people to take care of their health and maintain a slim figure through physical activity has brought a visible effect, expressed by the easily noticeable growing number of people benefiting from such activity. However, it sometimes happens that for some people sport becomes their central activity, while other activities - work, family, rest, hobbies - are reduced to a bare minimum. The regular exercises are performed notwithstanding the current health state, time, and even against doctor's orders in case of injury. Then, it becomes a case of addiction to physical exercise, compulsion or compulsive training (Guszkowska, 2012).

\section{MUSCLE DYSMORPHIA}

For some people, exercises become a way to achieve a goal, which is not improvement of health condition but obtaining a dream body figure. The current appearance becomes unsatisfactory, while the focus on the noticed defect is large. It is one of the symptoms of body dysmorphic disorder. The term dysmorphic disorder was introduced over 100 years ago by Morselli, who defined it as the subjective feeling of ugliness or the feeling of physical defect, while Kraepelin and Janet pointed out the compulsive nature of the disorder (Rabe-Jabłońska \& Wojtczak, 2006). Currently, the disorder exists in the ICD-10 classification (in the hypochondriac disorders group, WHO, 1992) and in DSMIV-TR - a somatoform disorder (APA, 2000). Many scientists indicate the similarity of body dysmorphic disorder to disorders from the obsessive-compulsive disorder (OCD) spectrum, but their nature and etiology are not identical (see e.g. Guszkowska, 2012; Rabe-Jabłońska \& Wojtczak, 2006). One type of body dysmorphic disorder is muscular dysmorphia, also known as bigorexia. It is characterised by dissatisfaction with one's muscular mass and body figure, and mostly affects men (Phillips, O'Sullivan, \& Pope, 1997; Pope, Gruber, Choi, Olivardia, \& Phillips, 1997).

Pope, Phillips and Olivardia (2000) indicate that in order to recognize muscle dysmorphia, two conditions must be fulfilled, according to the general DSMIV-TR criteria for body dysmorphic disorder. The first one is preoccupation with the idea that the body is not muscular and lean enough. It leads to behaviours aimed at gaining muscle mass (e.g. spending time on training additionally enhanced by taking special diet supplements and rigorously following a diet). The second one is that: a) the individual frequently forfeits important social, occupational and/or recre- ational activities because of the compulsive need to train hard, b) the individual actively avoids exposing the body, and c) if the avoidance of situations is not possible, the individual experiences a significant level of stress and/or anxiety. The preoccupation with inadequate body shape causes significant distress or sense of impairment in important areas of functioning. The last: the individual continues such behaviours despite the information of possible negative consequences (Olivardia, 2001).

Similarities between muscle dysmorphia and anorexia are often indicated, especially in the aspect of evaluating one's own appearance, disability to set the goal of exercises (being constantly too skinny or too fat) and a lack of belief in other people's opinion concerning the appearance. Because of this, muscle dysmorphia is often called a reversed anorexia (Mędraś \& Szczęsny, 2004; Pope et al., 2000; Starzomska \& Cylwik, 2013).

\section{CAUSES OF MUSCLE DYSMORPHIA}

Among the physiological causes, a hypothesis concerning the role of $\beta$-endorphins and other endogenous opiates is discussed, as well as the reactivity of the autonomous nervous system and the influence of catecholamine, though the research has not yet given an explicit answer (Guszkowska, 2012). It is a mechanism important in gym addiction, but in muscle dysmorphia it can be a cause of continuing behaviour despite negative consequences for special positive emotion from the body. Due to the similarities to OCD disorders, the role of serotoninergic and dopaminergic systems is pointed out; anomalies in central nervous system (CNS) are also searched for, mainly in the area of temporal and occipital lobes, which are connected to the rigidity of thinking (Rabe-Jabłońska \& Wojtczak, 2006). None of the hypotheses has been explicitly confirmed yet.

However, the most common indications of the causes of muscle dysmorphia are physiological and psychosocial. One reason from this group of causes, which is indicated among the possible determinants, is the contemporarily popularised body cult and fashion for a perfect figure. A comparison between one's own body and the desired standard emphasises the shortcomings and imperfections, which are seen as much more negative. This phenomenon is definitely much stronger during adolescence, when the pressure on our own attractiveness is very significant and, at the same time, physiological processes, which are typical for this age, cause unwanted changes in the appearance. This increases the anxiety of being judged and the negative self-image. If to the mentioned processes of valuating oneself unbeneficial childhood experiences are added, such as unsupportive, critical parents or being teased by peers based on the appearance, it
Muscle dysmorphia changes in self-image 
Dorota Mącik,

Monika

Kowalska-

Dąbrowska increases the negative self-esteem and it blocks the cognitive process of perceiving oneself. Then, the pursuit to achieve a perfect body appears, which seems to be the easiest way to show others one's value (Rabe-Jabłońska \& Wojtczak, 2006; Starzomska \& Cylwik, 2013; Rosen \& Reiter, 1996). The conceptual model of muscle dysmorphia is proposed by Grieve (2007), and it contains causes shown above with connections and dependences between them.

The results of the study indicate the relation between the feeling of happiness and the critical environment concerning the body image among men training in a gym (Starzomska \& Cylwik, 2013). The co-existence of these causes significantly increases the risk of muscle dysmorphia. It is estimated that $1-3 \%$ of the population suffer from body dysmorphic disorder and at least $10 \%$ of people who intensively train in a gym experience some symptoms of muscle dysmorphia (Mędraś \& Szczęsny 2004; Ulrych, 2013; Krzyżanowski, 2003; Melosik, 2010).

Taking into account the correlation between some muscle dysmorphia symptoms and training, the research question was stated:

$R$.Q. What kind of changes in self-image influenced by sport activities are noticed by people training regularly, who meet the dysmorphia criteria?

The answer to this question will allow one to state if it is really possible that in one's perception a low self-esteem is elevated during training and as a result of a change in physical appearance. At the same time, as it is known that the positive self-evaluation in some situations may be an overestimated assessment which performs a defence mechanism role such as rationalisation, it was decided also to examine the ideal self-image of people who train excessively. People with symptoms of body dysmorphia are typically not satisfied with the results of their efforts to compensate for the perceived flaw, because of the internal perceptual problems. It was thought that in case of positive changes between former and current self-image, if the current self-image is realistic, it would not be very different in the case of the ideal image. However, if, among the people examined, there is a risk or already existing muscle dysmorphia, connected with a self-evaluation disorder, the ideal image would still be very different from the current image. The following hypotheses were stated:

H1. There are significant differences between retrospective and actual self-image.

1.a The self-image from before starting gym training is more negative than the current one in the opinion of the subjects.

1.b Under the influence of training and change of figure the subjects describe themselves as more self-confident, dominating and less critical.

H2. The ideal self-image significantly differs from the current one. 2.a The number and the size of the differences between the examined images indicate further lack of self-acceptance.

\section{PARTICIPANTS AND PROCEDURE}

In order to verify the above hypotheses, the people under examination were asked to fill out questionnaires.

\section{MUSCULAR DYSMORPHIA SYMPTOMS - SCREENING SCALE}

The scale was a screening tool developed for this study and is only preliminary in nature yet. It was based on disorder criteria established by Pope (see: Mędraś \& Szczęsny, 2004). He distinguished the following criteria for recognising muscular dysmorphia:

- Preoccupation with a persistent thought that the body is not muscular enough,

- Spending many hours in a gym,

- Using a 'special' diet,

- Preoccupation with one's body structure causing a decline in performance in social, professional and all other vital fields,

- Avoiding situations in which a person with the disorder would have to show their body (a beach, a swimming pool),

- Continuing with the training and the diet while knowing it is not good for health and comfort.

These criteria were changed into six questions. For every question the answer was given on a Likerttype scale, where 1 means $I$ do not agree at all and 5 means I completely agree. The theoretical range of results was 6-30.

\section{ADJECTIVE CHECK LIST}

The Adjective Check List (ACL) is a questionnaire used to identify common psychological traits, developed by Harrison G. Gough and Alfred B. Heilbrun, Jr. It contains 300 adjectives. Respondents select the adjectives that they believe describe themselves. Any number of items may be selected from the list. In this way, the results are customized to include only those adjectives salient to the individual being assessed. The 300 adjectives correlate to 37 scales: 15 scales assessing needs or wants; 9 scales assessing attributes, potentialities, and role characteristics, 5 scales assessing transactional analysis, 4 assessing original-intelligence dimension and 4 assessing control scales. The ACL was used in the Polish adaptation by Martowska (2012). 


\section{PROCEDURE}

In the study there were firstly 85 people examined by the Muscular Dysmorphia Symptoms screening scale. All of them attended a gym regularly and were selected by sports instructors as being especially regular. In future analysis there were included only those people who obtained 27 point for the whole scale. It means that they choose mainly 4 and 5 point answers. Additionally, those who scored 1, 2 , or 3 point answers in any question were not taken for further examination. Finally 30 people were qualified for the further study. Results obtained by qualified people may indicate the risk of, or in some cases the existence of, dysmorphic disorder. There were 12 women and 18 men, with secondary or higher education, aged between 19 and 55. It was decided to include both men and women of such different ages to minimize the impact of these variables on the self-image (the correlation between sex, age and self-image is strong). Among the subjects examined a strong intensification in training can be noticed. The training sessions are undertaken at least four times a week, most of the examined people train 5 times a week and, for the majority of them, the time spent in a gym/fitness club is more than an hour for one session. It is worth noting that there is a group of people (16\%) who train every day (6-7 times) for over two hours. At the same time, several of the participants take part in other sport activities as well. Those people who have trained for at least 5 years were qualified for the study. The data are presented in Table 1.

The next scale, filled out by only 30 qualified people, was Gough's and Heilbrun's ACL questionnaire. Respondents fill out the scale three times, marking the adjectives answering the question: What were you like before starting regular training? What are you like now? and What would you like to be like?

To deepen the analyses, the following open questions concerning the experiences of the people involved in training were asked, which allowed them to answer freely:

- What was the reason for starting training in a gym/ fitness club?
- What are the benefits of going to the gym/fitness club for you?

- How do you feel when leaving after the training?

- How do you evaluate your social life?

The answers to open-ended questions were classified by expert judges (three clinical psychologists having experience in scientific research).

All of the examined people were informed about their legal rights, especially about anonymity, voluntariness and a possibility to refuse participation in the study at each stage. In the procedures the rules stated in the Helsinki Declaration were applied. Permission from the Bioethical Committee was not required. The study was not financed by any institution.

The acquired data were subjected to statistical calculations using the SPSS package. The results of data layout analysis allowed parametric methods to be used.

\section{RESULTS}

In order to check in which directions the self-image has changed (in people perception: under the influence of intensive training sessions), a retrospective image from before starting training (how the people actually think they were) was compared to the current evaluation. The results are presented in Table 2.

The significant differences presented in Table 2 suggest changes in self-perception; these changes are generally positive. However, it is not known if these changes are satisfactory, or if the people still have the need to improve their appearance. In addition, the current self-image may be overestimated and may perform a defence mechanism role. On the other hand, the retrospective image can also be distorted. People may use the rationalization mechanism to justify their efforts to change themselves. To obtain the answers for these doubts, the current image was compared to the ideal self-image. The acquired results are presented in Table 3.

The statistical analysis about self-image was enriched by the analysis of the answers given by the subjects examined on the questions asked. Table 4 presents the reasons for undertaking training and
Muscle dysmorphia changes in self-image

Table 1

Frequency and training time of the subjects examined

\begin{tabular}{lcccccccc}
\hline $\begin{array}{l}\text { Number } \\
\text { of work-outs } \\
\text { a week }\end{array}$ & $N$ & $\%$ & $\begin{array}{c}\text { Training } \\
\text { time }\end{array}$ & $N$ & $\%$ & $\begin{array}{c}\text { Other } \\
\text { classes }\end{array}$ & $N$ & $\%$ \\
\hline 4 times & 11 & 36.67 & $<1$ hour & 3 & 10.00 & Yes & 4 & 13.33 \\
5 times & 14 & 46.67 & $1-2$ hours & 22 & 73.33 & & & \\
6-7 times & 5 & 16.67 & $>2$ hours & 5 & 16.67 & No & 26 & 86.67 \\
total & 30 & 100.00 & total & 30 & 100.00 & & &
\end{tabular}


Table 2

Significance of differences in ACL measurements in retrospective and current self-assessment

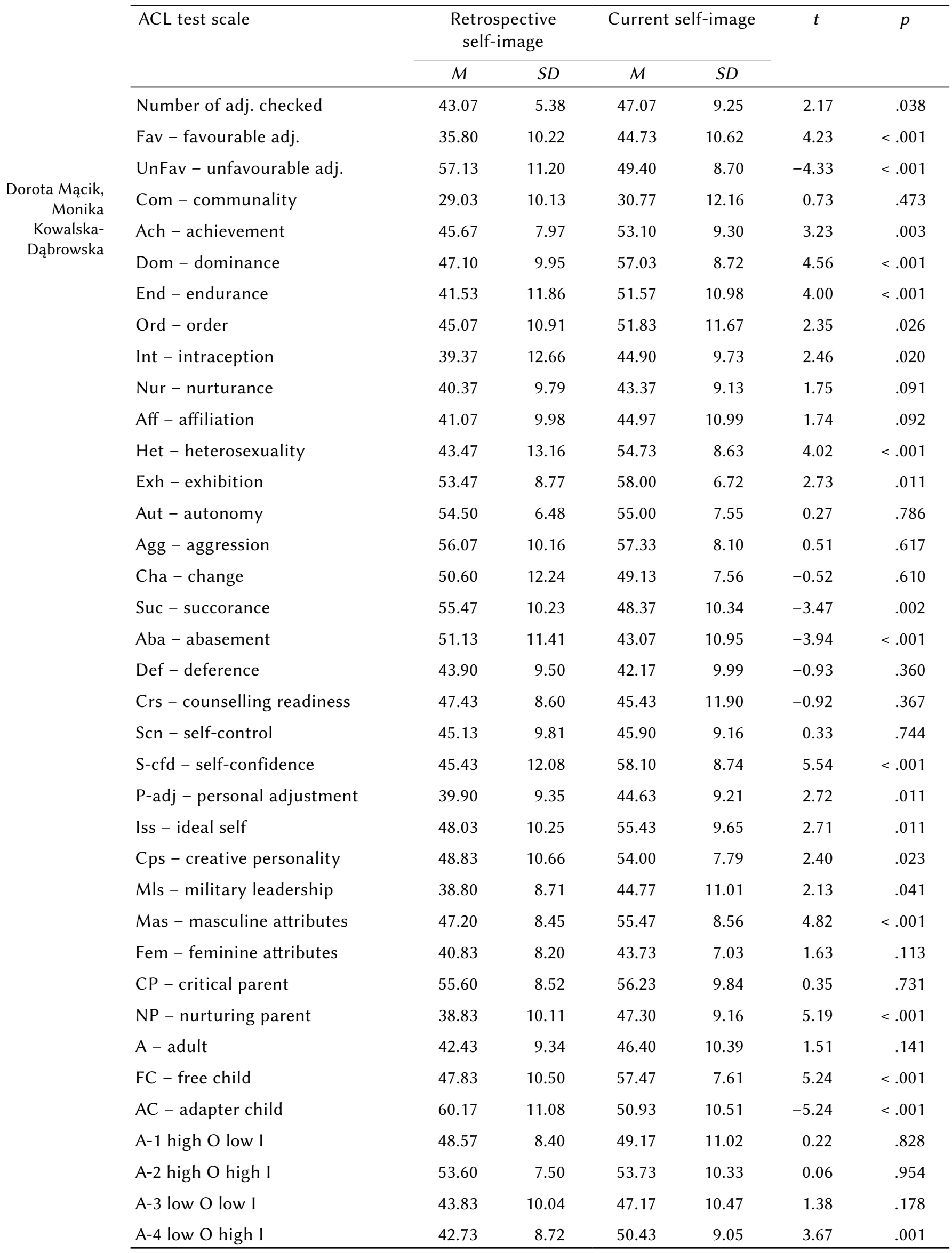


Table 3

Significance of differences in ACL measurements in current and ideal self-assessment

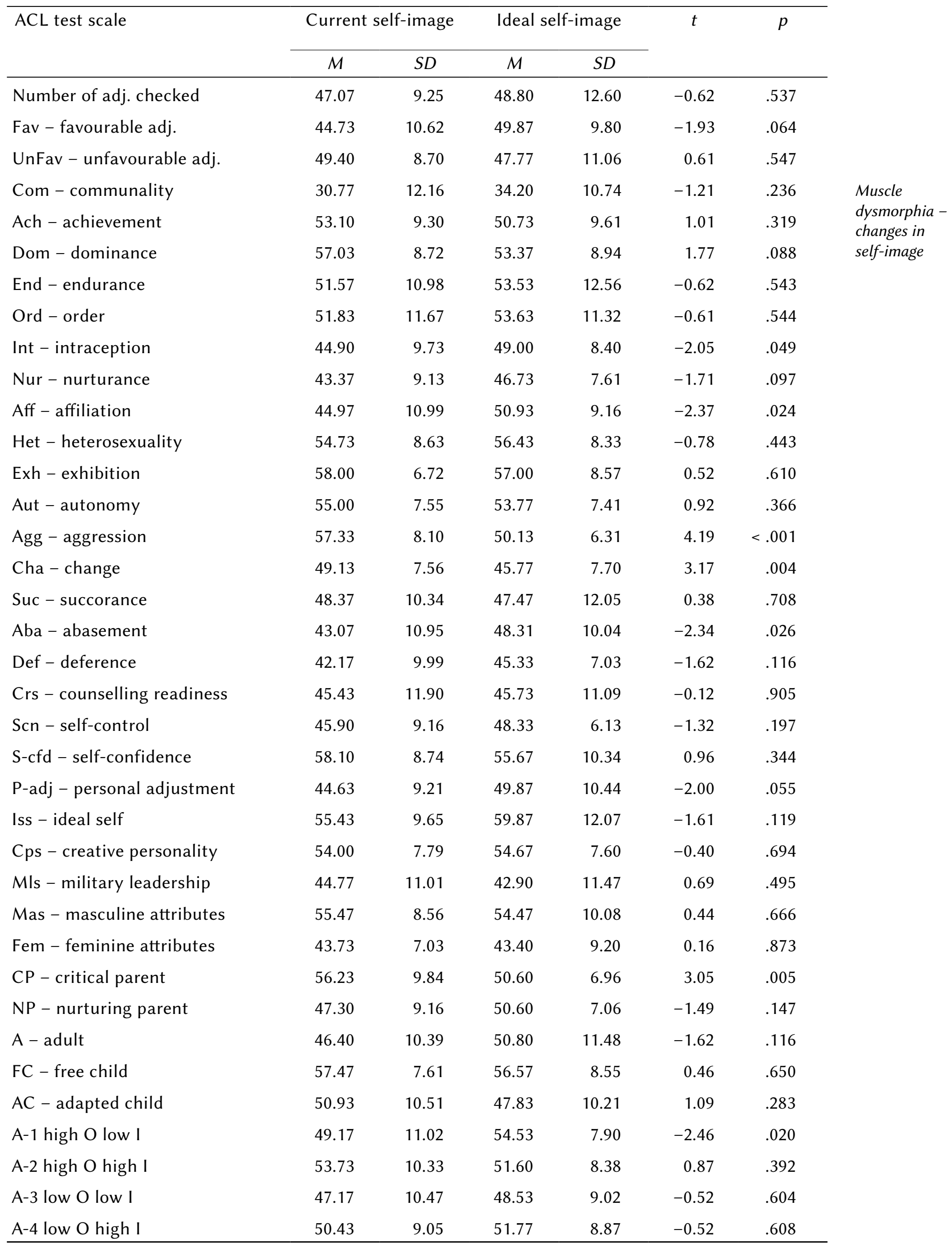


Table 4

Reasons for undertaking workouts

\begin{tabular}{lcc}
\hline $\begin{array}{l}\text { What were the reasons } \\
\text { for doing training }\end{array}$ & $N(30)$ & $\%$ \\
in the gym/fitness club? & 28 & 93.33 \\
\hline Figure improvement & 26 & 86.67 \\
Physical fitness improvement & 17 & 56.67 \\
Better self-feeling & 14 & 46.67 \\
Health improvement & 12 & 40.00 \\
Friend's/partner's advice & 4 & 13.33 \\
\hline
\end{tabular}

their feelings on that showed certain characteristic features.

Table 5 shows the answers to the question on advantages gained from attending the gym/fitness club.

Table 6 presents emotions experienced by examined people after finishing the work-out.

The last question was about the social life of study participants. As Table 7 shows, their assessment of this part of life is rather negative.

\section{INTERPRETATION AND DISCUSSION OF RESULTS}

Above all, it should be noted that the examined people assessed their actual self-image as more positive in the general assessment compared to the retrospective one. They choose much more positive adjectives to describe themselves; therefore, they have become more open and accepting of themselves, which is additionally confirmed by the significant growth in the number of positive adjectives with a simultaneous, also very significant, drop in negative adjectives being chosen $(p<.001)$.

The detailed analysis of self-image features indicates very numerous significant differences between retrospective and actual self-image. In the aspect of needs, the people became more self-confident. The need for achievement (Ach) has grown a lot; its driving force may have been the directly visible effects of training. It was similar in the case of endurance, the growth of which is based on the physical experience of positive results of consistent activity. These features, though desirable in one's self-image and generally providing positive social functioning, in the case of extensive use of a gym may lead to setting more goals to achieve, while the method of achieving these goals may be connected with a loss of control over training, all the more so that the dominance has also grown significantly, which may cause these people to be very resistant to suggestions and criticism from other people.
Table 5

Advantages felt as a result of training

\begin{tabular}{|c|c|c|}
\hline $\begin{array}{l}\text { What are the advantages for } \\
\text { you of attending gym/fitness } \\
\text { club classes? }\end{array}$ & $N(30)$ & $\%$ \\
\hline Self-confidence & 29 & 96.67 \\
\hline 'More attractive' figure & 28 & 93.33 \\
\hline Better self-feeling & 25 & 83.33 \\
\hline Detachment from reality & 24 & 80.00 \\
\hline $\begin{array}{l}\text { Popularity among opposite sex/ } \\
\text { physical attractiveness }\end{array}$ & 17 & 56.67 \\
\hline Friends with similar interests & 12 & 40.00 \\
\hline
\end{tabular}

Table 6

Feelings experienced after finishing training

What do you feel when leaving $N(30) \quad \%$

the gym after finishing

training?

\begin{tabular}{lcc}
\hline Satisfaction & 28 & 93.33 \\
Tiredness & 27 & 90.00 \\
Strength/power & 26 & 86.67 \\
Willingness to check yourself & 14 & 46.67 \\
Impatience & 11 & 36.67 \\
Quietness & 9 & 30.00 \\
Insufficiency & 4 & 13.33 \\
\hline
\end{tabular}

Table 7

Assessment of social life quality among the subjects examined

\begin{tabular}{lcc}
\hline $\begin{array}{l}\text { How do you assess your social } \\
\text { life? }\end{array}$ & $N(30)$ & $\%$ \\
\hline Poor - lack of time & 18 & 60.00 \\
Medium - I have a few friends & 7 & 23.33 \\
Very good & 5 & 16.67 \\
\hline
\end{tabular}

This independence is also visible in a decline of the excessive need of feeling support and humiliating oneself. In their assessment, the people under examination have changed from being dependant, searching for help, uncertain of themselves, conditioning the decisions on others or the external situation, to being people who can decide for themselves, who are convinced about their independence and also who are a little less concerned about the needs of others.

Regarding the social aspect in the sphere of needs, a significant need for heterosexual contacts and ex- 
posure should be noted, as well as statistical tendencies of growth in affiliation and caring needs. So long as the results in the aspect of exposure are very high, the last two needs remain - despite some growth - still in the area of a little lower results. Such arrangement would suggest a strong tendency, among the subjects examined, to talk about themselves, to show off, also in the aspect of intersexual relations, though relating it to the other features, such as the above mentioned tendency to dominate or the constantly elevated aggression - the exposure would perform the role of searching for confirmation of one's achievements and accomplishments, convincing others of one's achievements, and proving one's superiority (changes in abasement [Aba] may also suggest a need for proving to oneself and to others that the subjects examined are now "better" than their acquaintances).

In this regard, relatively low results in the aspect of need for affiliation and caring, as well as interception, indicate that the people under examination do not care about bonding based on mutual understanding and acceptance, in which accepting support does not imply weakness which the subjects examined avoid.

In the aspect of needs, intensive training and building one's figure influenced the transfer of the self-image accent from people who are a little lost, uncertain, and self-critical to people who are at least externally domineering, self-confident, convinced of their attractiveness and wanting other people to think the same way. However, the relatively low interception (Int) and the fear of dependency (Def) suggest the possibility that this change is mostly external, whereas the training and its influence on seeing oneself partly perform a defence mechanism role, being an escape from experiencing one's lack of acceptance and a fear of being unaccepted by others. The thesis may be confirmed by the lack of differences in the aspect of the need for change, which indicates that the subjects examined feel that they are really not much changed - if the observed change was real and positive, the intensification of the need to make changes in oneself and one's surroundings would fall, but it did not. However, at the same time, in comparison to other results, the need for aggression is constantly high, which suggests that these people are still not satisfied with themselves and with the world. It also draws attention to the differences between the two images in the defence mechanism, mainly as retrospective image distortion. Moreover, it indicates that the observed differences are probably not real changes, but only perceived ones.

In the aspect of subject scales, there can be observed significant growth in trust in oneself, personal adaptation, ideal self-image, creative abilities, leadership abilities and masculine features. The group of results being higher in the scale of trust in oneself and masculinity indicates the sense of certainty and the conviction of making the right choices. They are perceived as ambitious, and, at the same time, they do not cope with frustration well, and they take quick action, which is an important manner of performing for them. However, it sometimes happens that these actions are aimed mostly at making a good impression on others. It may serve the mechanism of changing the image from being rather shy, restrained and not taking the initiative to believing in oneself and being active.

Although the result in personal adjustment (P-adj) has grown significantly, it still remains in the area of lower results, which suggests the internal timidity of those people and the avoidance of having close relations with others.

The characteristic result is almost complete lack of change in the area of self-control - the result remains relatively low in comparison to other results of the profile. It indicates that the subjects examined, despite some sense of duty, endurance or pursuing achievements, are internally still having problems controlling their impulsivity. It probably partly results from a relatively low need for intraception. On the other hand, it can be assumed that there is some kind of an impulsive need based on intensive training, which having been awoken by the training determines in a way its satisfaction, which is indicated by strong intensity of training and fulfilling the criteria of addiction by the subjects under examination. Each addiction is based on a problem with controlling emotions and actions.

In the scope of transactional analysis, we may observe a considerable increase in the scale of a nurturing parent which could indicate the increase in the assessment of one's capabilities of adapting to others and searching for relations. The needs, however, are dominated by a critical parent - although there is no change in the intensity, the scale shows increased results. This indicates that the subjects examined have not changed, under the influence of exercises, the way they perceive themselves as impulsive and sceptical persons, with a critical approach to others rather narcissistic types. Maintaining intensification of this measurement with simultaneous increase of a nurturing parent prompts one again to consider the power of defence mechanisms and inner uncertainty as to the real motives which drive other people.

It is also worth drawing attention to the fact of a total reversal of AC and FC scales' relations. Although AC definitely prevailed over FC in a retrospective image, presently it is exactly the other way around. The subjects examined, from persons who are not self-reliant, dependent, avoiding confrontations, fearing stress and frustration, preferring coping with life by escaping to dreams, became, in their own eyes, adventurous, open persons who are bound for immediate satisfaction of their needs. Other people perceive them as quite interesting but aggressive at the same time.
Muscle dysmorphia changes in self-image 
In the Welsh's origence-intellectence scales, a change in intelligence is noted in only one scale, A-4, suggesting learning that discipline, planning, keeping to the plan and hard work allow one to achieve the goals set.

Control comparison of current and ideal image, the results of which are presented in Table 3, leads to interesting conclusions. First of all, the number of differences between the images analysed is definitely smaller than in the case of the previous comparison. As this discrepancy is not that high, it can be assumed that many of the expectations that the subjects examined had when starting their training were met. It also seems that their self-assessment is quite realistic. They believe that they are too dominating in relations with others and that they have two many negative feelings, including those towards others. The assess themselves as excessively critical, both towards themselves and others. They feel the need for better understanding of themselves and the associated need for more effective functioning. At the same time they still express their great demand for other people's acceptance (affiliation - Aff), being still convinced that they do not deserve it for many different reasons (Aba). This composition of features seems to be desirable and realistic. However, in comparison to the amount of time spent on training (which is every day, over 1 hour for most of the subjects examined) and the fact that all of them obtained higher results in Pope's criteria of recognising muscle dysmorphia, it is probable that their belief of being worse than others will be the cause of continuing training as this feeling concerns not only physical but - above all psychological aspects, and the strong need for affiliation will be of additional motivation.

The statistical analysis was enriched by the analysis of the answers given by the subjects examined on the questions asked. Their answers concerning the reasons for undertaking training and their feelings on that showed certain characteristic features (Table 4).

Categorisation of their answers shows that the main reason for starting training is connected with figure improvement (over 95\%). Dissatisfaction with one's body, similarly as in the case of anorexia, may lead to poor self-control and insight, which are so characteristic for the subjects examined, and to a loss of control over exercise intensity. It is consistent with DSM-IVTR criteria of muscle dysmorphia (APA, 2000). Excessive concentration on appearance and striving continuously to improve the figure or musculature limit the insight into psychological needs, which become subordinate to or even dependent on the physical state. This condition can be potentially dangerous and bears a risk of dysmorphic disorders. The drive to increase body shape and muscles is connected with negative emotions (McCabe \& Ricciardelli, 2004).

The other reasons refer also to physical reasons such as improving physical fitness, health improve- ment or just generally better self-feeling. These are quite rational reasons and they do not raise any anxiety themselves. However, when matched with a specific set of personality traits, they may become a potential moderator of excessive exercises due to the fact that positive results achieved (health improvement, better figure, nicer self-feeling) become positive reinforcement and they tend to repeat their actions.

This reasoning seems to be supported by answers to questions on advantages gained from attending the gym/fitness club (Table 5).

The vast majority of the subjects examined indicate the effects directly connected with psychic condition. Formally, physical activity does not directly cause a higher level of self-confidence. If, however, $96 \%$ of the subjects examined indicate that exercises give them more self-confidence, it can be assumed that they de facto realize the other need than the one given as a primary reason for practising physical exercises. This change may be - and probably in many cases is - unconscious. Benefits resulting from intensive exercises also include better psychic self-feeling and the possibility of detaching from reality. It means that for many people, going to a gym or fitness club helps them to cope with difficult situations of everyday life. It is not a problem and is an acceptable way of coping as long as it is an additional effect. However, if it becomes a fundamental method of coping with difficulties, it may become a potential cause of difficulties.

Spontaneous description of emotions after finishing the work-out is a characteristic feature (Table 6).

As many as $93 \%$ of the subjects examined say that they feel satisfaction, and this result is higher than tiredness, which is a natural condition after intensive physical effort. Satisfaction, to some degree, originates from overcoming physical limitations; however, it co-exists with power and strength, which specifically refer to psychological feelings. Some people indicate quietness, which could mean overcoming some difficulties or anxieties.

However, it is worth noting that over $36 \%$ of the subjects examined feel impatience and $13 \%$ feel insufficiency. These are the feelings connected with addiction or considerable risk of addiction to physical exercises, and they may be potentially connected with the risk of muscle dysmorphia. Their occurrence means that some needs have not been satisfied. Failing to reach goals can increase the negative affect (Powers, Koestner, Lacaille, Kwan, \& Zuroff, 2009).

The subjects examined assess their social life, at the same time, as poor, and they connect it with lack of time (Table 7). On the other hand, they are able to find time every day or almost every day for a long training session. It would indicate meeting one criterion of addiction to exercises according to which excessive involvement in training negatively affects social life. 
The above analyses lead us to confirm hypothesis 1 , as well as sub-hypotheses 1a and 1b. Regular physical exercises make people describe themselves as having changed from reserved, uncertain and critical persons towards persons who are dominating and assess themselves in positive categories. But, because of the need to justify one's activity, the retrospective self-description can be worse than it was in fact.

The results also show that the perceived change in the self-image is of at least partly outer nature, and, in some way, this change is a defence mechanism. The persons who were weaker inside, through their systematic exercises, achieved measurable physical change in the bodily aspect of self-image. This change gave grounds for the feeling - difficult in this study to say how deep - of changes in the psychic structure. These results, therefore, correspond to the literature, where muscle dysmorphia is indicated to develop among persons assessing themselves as worse, and the improvement of physical image is to contribute to the improvement of global self-assessment (Olivardia, 2001; Leone, Sedory, \& Gray, 2005; McCabe \& Ricciardelli, 2004; Powers et al., 2009).

The studies of Starzomska and Cylwik (2013) show the relation of perceived criticism to the feeling of happiness and reasonableness of life of the men examined. Presently, the studies, in particular, of the analysis of the ideal self-image seem to confirm that sensitivity to criticism hinders full acceptance of oneself. Mącik, Ziółkowska, and Kowalska (2012) observe that, not once, a positive self-image in a difficult psychological situation plays only the role of a defence mechanism. This role of the current self-image is also observable in the examination, because at least partly, the way of perceiving oneself is focused on the other people's expectations about proper behaviour. The subjects examined themselves, however, are not totally convinced of it, which is shown in Aba, Int and Cha results. Hypothesis 2 has not been explicitly confirmed - not numerous differences and their extent indicate achieving self-acceptance by the subjects examined. However, the clinical view of the scale composition proves that, in some parts of it, it is a superficial acceptance, and the problems causing this excessive involvement in exercises have not been solved. The detailed analysis of these problems, their intensification and origin with the qualitative assessment of benefits observed in the aspect of their solving requires continuation of studies in this range (Wolke \& Sapouna, 2008).

Considering that the assessment of changes which occurred in self-perception in time is connected directly with undertaking exercises in a gym, there is a risk that they will have to be maintained throughout the whole time of training. It may lead to increased exercise intensity and the development of addiction. Some of them, probably, will face the risk of full-symptom dysmorphic disorder (muscle dysmorphia) (Mosley, 2009; Leone et al., 2005; Grieve \& Helmick, 2008).

Generally, it should be noted that the results obtained correspond to the model of Grieve's muscle dysmorphia (Grieve, 2007). It is mainly visible in the perceived changes of self-esteem and its relation to the time spent on training. In this preliminary study there were only some psychological factors, emotions and time of training, examined in the people without the muscle dysmorphia diagnosis. The obtained results are a good background to explain the muscle dysmorphia problem much more deeply, with the variables of Grieve's model.

\section{References}

American Psychiatric Association (2000). Diagnostic and Statistical Manual of Mental Disorders ( $4^{\text {th }}$ ed., text rev.). Washington, DC: Authors.

Grieve, F. G. (2007). A conceptual model of factors contributing to the development of muscle dysmorphia. Eating Disorders, 15, 63-80.

Grieve, R., \& Helmick, A. (2008). The influence of men's self-objectification on the drive for muscularity: self-esteem, body satisfaction and muscle dysmorphia. International Journal of Men's Health, 7, 288-298.

Guszkowska, M.(2012). Uzależnienie odćwiczeńfizycznych - objawy $i$ mechanizmy [Exercise dependence - symptoms and mechanisms]. Psychiatria Polska, 46, 845-856.

Krzyżanowski, J. (2003). Natręctwa, obsesje i kompulsje [Intrusivenesses, obsessions and compulsions]. Warszawa: Wydawnictwo Medyk.

Leone, J. E., Sedory, E. J., \& Gray, K. A. (2005). Recognition and treatment of muscle dysmorphia and related body image disorders. Journal of Athletic Training, 40, 352-359.

Mącik, D., Ziółkowska, P., \& Kowalska, M. (2012). Self-perception of women after mastectomy as an ego defence mechanism. Comparison with a group of healthy women. Contemporary Oncology, 16, 184-190.

Martowska, K. (2012). ACL - Lista przymiotnikowa [ACL - Adjective Check List]. Warszawa: PTP.

McCabe, M. P., \& Ricciardelli, L. A. (2004). Weight and shape concerns of boys and men. In: J. K. Thompson (ed.), Handbook of eating disorder and obesity (pp. 606-634). Hoboken, NJ: Wiley \& Sons.

Mędraś, M., \& Szczęsny, M. (2004). Dysmorfofobia (dysmorfia) mięśniowa a sport [Muscle dysmorphophobia (dysmorphia) and sport]. In: M. Mędraś (ed.), Medycyna sportowa [Sports Medicine] (pp. 109-110). Warszawa: Medsportpress.

Melosik, Z. (2010). Tożsamość, ciało i władza w kulturze instant [Identity, body and the power in the "instant" culture]. Kraków: Impuls.
Muscle dysmorphia changes in self-image 
Mosley, P. E. (2009). Bigorexia: Bodybuilding and muscle dysmorphia. European Eating Disorders Review, 17, 191-198.

Olivardia, R. (2001). Mirror, mirror on the wall, who's the largest of them all? The features and phenomenology of muscle dysmorphia. Harvard Review of Psychiatry, 9, 254-259.

Phillips, K. A., O’Sullivan, R. L., \& Pope, H. G. Jr (1997). Muscle dysmorphia. Journal of Clinical Psychiatry, 58, 361.

Dorota Mącik,

Pope, H. G., Gruber, A., Choi, P., Olivardia, R.,

Monika

Kowalska-

Dąbrowska \& Phillips, K. (1997). Muscle dysmorphia. An underrecognized form of body dysmorphic disorder. Psychosomatics, 38, 548-557.

Pope, H. G., Phillips, K. A., \& Olivardia, R. (2000). The Adonis Complex: The secret crisis of male body obsession. New York: The Free Press.

Powers, T., Koestner, R., Lacaille, N., Kwan, L., \& Zuroff, D. (2009). Self-criticism, motivation, and goal progress of athletes and musicians: A prospective study. Personality \& Indyvidual Differences, 47, 279-283.

Rabe-Jabłońska, J., \& Wojtczak, K. (2006). Dysmorfofobia. Kryteria diagnostyczne, etiologia, rozpowszechnienie, obraz kliniczny, przebieg i leczenie [Body dysmorphic disorder: diagnostic criteria, etiology, clinical picture, course and therapy]. Psychiatria w Praktyce Ogólnolekarskiej, 6, 42-49.

Rosen, J. C., \& Reiter, J. (1996). Development of the body dysmorphic disorder examination. $B e^{-}$ haviour Research and Therapy, 34, 755-766.

Starzomska, M., \& Cylwik, M. (2013). W poszukiwaniu przyczyn bigoreksji: Wizerunek ciała a dobrostan u mężczyzn uczęszczających do siłowni w świetle wyników badań własnych [Body image and wellbeing among men attending the gym empirical study]. Kwartalnik Naukowy, 13, 204-217.

Urlych, I. (2013). Wielka bigoreksja - w wielkiej sieci [The great bigorexia - on the World Wide Web]. Wychowanie Fizyczne i Zdrowotne, 1, 20-25.

Wolke, D., \& Sapouna, M. (2008). Big men feeling small: Childhood bullying experience, muscle dysmorphia and other mental health problems in bodybuilders. Psychology of Sport \& Exercise, 9, 595-604.

World Health Organization (1992). The ICD-10 classification of mental and behavioural disorders: clinical descriptions and diagnostic guidelines. Geneva: Authors. 